\title{
Resgate das relações abusivas em que nos encontramos: uma questão de prevenção quinquenária
}

\author{
Rescue from the abusive relations in which we found ourselves: a matter of quinquenary prevention \\ Rescate de las relaciones abusivas en que nos encontramos: un asunto de prevención quinquenaria
}

José Agostinho Santos ${ }^{1}$

1 Unidade de Saúde Familiar Dunas (ULS). Matosinhos, Portugal.

\section{Resumo}

O conceito da prevenção quinquenária coloca a qualidade de vida dos profissionais na perspectiva dos cuidados prestados ao paciente. Os dados relativos à prevalência da síndrome de burnout entre os profissionais de saúde têm sido considerados preocupantes. Este artigo coloca a possibilidade de a condição-base essencial para o surgimento do burnout ser a integração em relações abusivas, isto é, relações caracterizadas por desigualdade entre os dois polos e em que não há oportunidade para os profissionais ativarem os seus papéis de expressão, criatividade, reconhecimento ou autoconhecimento em cada momento. Profissionais que se conhecem, reconhecidos, que expressam livremente as suas ideias e necessidades serão, provavelmente, profissionais que tomarão decisões mais assertivas, ponderadas e com menos erros no cuidado do próximo.

Palavras-chave: Promoção da Saúde; Esgotamento Profissional; Erros Médicos

\section{Abstract}

The concept of five-year prevention puts the quality of life of professionals in the perspective of the care provided to the patient. Data on the prevalence of burnout syndrome among health professionals have been considered alarming. This article raises the possibility that the essential basic condition for the emergence of burnout is the integration into abusive relationships, that is, relations characterized by inequality between the two poles where there is no opportunity for professionals to activate their roles of expression, creativity, recognition or self-knowledge at every moment. Knowledgeable, wellknown professionals who freely express their ideas and needs are likely to be professionals who will make more assertive, thoughtful decisions and with fewer mistakes in caring for others.

Keywords: Health Promotion; Burnout, Professional; Medical Errors
Como citar: Santos JA. Resgate das relações abusivas em que nos encontramos: uma questão de prevenção quinquenária. Rev Bras Med Fam Comunidade. 2019;14(41):1847. https://doi.org/10.5712/rbmfc14(41)1847

\author{
Autor correspondente: \\ José Agostinho Santos. \\ E-mail: zeagostinho@hotmail.com \\ Fonte de financiamento: \\ declaram não haver. \\ Parecer CEP: \\ não se aplica. \\ Procedência e revisão por pares: \\ revisado por pares. \\ Recebido em: 25/08/2018. \\ Aprovado em: 24/06/2019.
}




\section{Resumen}

El concepto de la prevención de cinco años coloca la calidad de vida de los profesionales en la perspectiva de los cuidados prestados al paciente. Los datos relativos a la prevalencia del síndrome de burnout entre los profesionales de la salud se han considerado preocupantes. Este artículo plantea la posibilidad de que la condición-base esencial para que el surgimiento del burnout sea la integración con las relaciones abusivas, es decir, relaciones caracterizadas por desigualdad entre los dos polos y en que no hay oportunidad para que los profesionales activen sus papeles de expresión, creatividad, reconocimiento o auto-conocimiento en cada momento. Los profesionales que se conocen a sí mismos, son reconocidos y que expresan libremente sus ideas y necesidades serán, probablemente, profesionales que tomarán decisiones más asertivas, ponderadas y con menos errores en el cuidado de los demás.

Palabras clave: Promoción de la Salud; Agotamiento Profesional; Errores Médicos

\section{Prevenção quinquenária}

Em 2014, o conceito da prevenção quinquenária foi proposto em publicação científico-médica portuguesa e, desde então, a comunidade médica em Portugal o tem integrado em seus artigos de opinião e nas mesas de discussão em encontros médicos. ${ }^{1-3}$

As linhas da prevenção quinquenária foram apresentadas em associação com o mote "prevenindo o dano no paciente, atuando no médico", introduzindo um novo nível de medidas preventivas que, tal como outros níveis de prevenção (primordial, primária, secundária, terciária e quaternária), visa à melhoria da qualidade dos cuidados e da saúde nos pacientes, porém com foco no cuidador, de onde, efetivamente, emergem todos os cuidados. ${ }^{1}$

Não é novidade que "cuidadores cuidados" prestam cuidados de melhor qualidade a quem cuidam. Tal salienta que, em última instância, entre os beneficiados estão os pacientes, muito embora as questões relativas ao bem-estar, qualidade de vida ou saúde do próprio médico ou profissional de saúde tenham sido delegadas para os próprios profissionais e tendencialmente colocadas fora do espectro clássico das atitudes preventivas sobre os pacientes ou a população. ${ }^{4}$

O conceito da prevenção quinquenária coloca a qualidade de vida dos profissionais na perspectiva dos cuidados prestados ao paciente e, assim, todas as matérias nele incluídas (e desde há muitos anos debatidas) como o síndrome de burnout, passam a ter um âmbito alargado, com a necessidade de intervenção de diferentes entidades, e a não ser apenas do interesse exclusivo do médico. ${ }^{1,4}$ Coloca também as ações de prevenção quinquenária numa plataforma de importância similar às medidas de prevenção primordial, primária, secundária, terciária e quaternária.

Poder-se-á distribuir as estratégias no âmbito da prevenção quinquenária por quatro níveis principais:

- A nível do médico/profissional de saúde

- A nível do paciente

- A nível do local de trabalho

- A nível da administração/tutela/governo

Em cada nível estratégico, haverá diferentes agentes de intervenção. Neste artigo, iremos focar no papel ativo que o profissional de saúde terá nas quatro áreas, embora esse mesmo papel ativo pressuponha atividades diferentes em cada esfera. 


\section{O papel ativo}

Assim, a nível governamental ou da tutela, estabelecem-se estratégias desenvolvidas na perspectiva do profissional enquanto funcionário de uma instituição e que integram a adequação dos contratos nas instituições públicas ou privadas quer sob o prisma remuneratório quer sob o prisma de horário (cumprimento das horas de pausa, evicção de sobrecarga laboral com horas extraordinárias ou exequibilidade do número de consultas por hora, permitindo ao profissional ter tempo para o seu autocuidado). ${ }^{1,5}$

Estas medidas podem ser iniciadas num movimento unido dos profissionais junto de plataformas comuns - como as ordens, associações ou sindicatos - que os possam representar em reuniões com membros governamentais. Um papel ativo de EXPRESSÃO das suas necessidades é, assim, essencial por parte do profissional de saúde.

A nível do local de trabalho, as estratégias poderão criar um campo para expressão máxima da faceta profissional do trabalhador de saúde e incidirão no incremento qualitativo das condições de trabalho (como recursos humanos adequados às necessidades populacionais, disponibilidade de materiais e de equipamentos tecnológicos funcionais, programas informáticos que criem um suporte intuitivo de registro e pesquisa clínica, instalações especialmente arquitetadas para um cuidado em saúde personalizado e que permitam o sigilo e a privacidade do paciente, elaboração de consensos interpares de atuação clínica e de articulação multiprofissional ou, não menos relevante, criação de momentos de lazer em equipe e que são correntemente denominados de momentos de team building). ${ }^{1,5,6} \mathrm{Um}$ papel ativo de CRIATIVIDADE é aqui necessário por parte do profissional de saúde.

A nível do paciente, incluem-se medidas que possam gerar uma transformação mais ou menos significativa a nível da comunidade e que possam ser facilitadoras da comunicação médico-paciente logo desde o primeiro momento de consulta. Aqui residem planos estratégicos que englobam um sutil convite ao paciente para ter um papel mais consciente na relação que estabelece (relação médico-paciente, enfermeiro-paciente ou outra) e valorizar esta relação.

Há mitos em saúde criados na sua comunidade, preconceitos gerados em si devido às suas histórias pessoais e perspectivas adulteradas pela força da publicidade ou da mídia que transporta para o seio de uma relação e que podem corroer a comunicação entre os dois intervenientes. O profissional médico poderá, por exemplo, desenvolver ações de formação pública ou de sensibilização para questões clínicas que lhe pareçam prementes na redução do chamado disease mongering ou na atenuação do alarmismo público passível de ser gerado em temas particulares. ${ }^{1,7}$ Um papel ativo do profissional de RECONHECIMENTO como um dos dois polos de uma relação profissional de saúde - paciente que estabelece é fulcral.

Finalmente, dentro do nível interno do profissional encaixam-se todas as estratégias que potenciem uma expansão do conhecimento das suas necessidades intrínsecas enquanto ser humano, com o seu passado e seus desejos/feridas/prazeres/padrões, e de como tais necessidades são relevantes para o seu desempenho e relações em qualquer esfera da sua vida, incluindo profissional. Estas medidas incitam, também, um autocuidado por parte do profissional (estabelecer bons estilos de vida com tempo para exercício físico, boa nutrição, reflexão pessoal, trabalho interno...). ${ }^{4,6,8} \dot{E}$ absolutamente primordial que o profissional tenha um papel ativo de AUTOCONHECIMENTO. 


\section{As relações abusivas}

Nos últimos anos, têm sido publicados estudos sobre a prevalência da síndrome de burnout entre os profissionais de saúde em diferentes países e os resultados têm sido considerados preocupantes. ${ }^{4}$ Também inúmeros artigos têm sido editados acerca desta temática, evidenciando que há perspectivas muito diversas que propõem estratégias variadas na sua abordagem, incluindo opiniões de vários investigadores provindos de diferentes categorias profissionais que estão muito envolvidos no estudo e na vivência da síndrome de burnout.

Este artigo de opinião apenas expõe mais um ponto de vista acerca do desgaste entre os profissionais de saúde, permitindo, quiçá, alargar o campo de discussão sobre o tema ou a prevenção quinquenária. $\mathrm{E}$, de uma forma relativamente sucinta, este artigo coloca a possibilidade de a condição-base essencial ("semente") para o surgimento do burnout do profissional ser a sua integração em relações abusivas, isto é, relações caracterizadas por desigualdade ou desnivelamento entre os dois polos da ligação e em que um (ou os dois simultaneamente) não tem uma oportunidade ou um campo de ativar os seus papéis de expressão, criatividade, reconhecimento ou autoconhecimento em cada momento.

Nenhuma espécie vegetal emerge sem terreno fértil e sem tempos de germinação ou crescimento, pelo que também a síndrome de burnout não tem surgimento súbito (até porque cumpre a triangulação dimensional que classicamente o define: exaustão emocional, despersonalização e diminuição da realização pessoal) e necessita do seu campo fértil para germinar. Seria, talvez, importante que diversas medidas preventivas pudessem modular esse campo que apenas é fértil porque o profissional mantém as suas relações abusivas dentro de qualquer um dos quatros níveis da prevenção quinquenária.

Na opinião do autor, a integração do profissional de saúde em relações desiguais poderá ser muito subtil e facilitada por diversas circunstâncias dos dias atuais. Referem-se aqui as relações abusivas que o profissional estabelece com a entidade governamental ou a tutela ao aceitar contratos injustos, precários, sobrecarregados e debaixo de uma tônica de opressão e de contração da sua criatividade quando não tem plataforma para expressar as suas necessidades ou propostas de mudança. É já sobejamente conhecido que a sobrecarga laboral leva a um progressivo desgaste emocional. , $, 5,8^{2}$

Também se destacam as relações disfuncionais que estabelece com os seus colegas de trabalho (ao manter conflitos que desviam o respeito mútuo ou a colaboração em equipe), que não são saudáveis para nenhuma das partes e que causam exaustão mental. Existem ainda as relações desiguais que estabelece com os pacientes: quer na desigualdade de cuidados que podem ser prestados sob um paternalismo desmedido que privilegia as ordens em detrimento das decisões negociadas entre os dois (com consequente prejuízo na compliance e adulteração dos planos terapêuticos) quer no desnivelamento induzido pelo seu receio de cobrança ou acusação por parte dos pacientes descritos como complexos ou difíceis. ${ }^{9} \mathrm{~A}$ frustração e a insegurança incitam uma despersonalização gradual do "eu-clínico" que habita o profissional.

Finalmente, evidencia-se aquela que é, na opinião do autor, a mais relevante relação abusiva e danosa em que o profissional se insere: a relação abusiva consigo próprio. Uma forte relação abusiva consigo mesmo (muitas vezes caracterizada por uma agressiva autocrítica indutora de uma insegurança 
interna) retira-Ihe uma visão justa acerca do seu valor próprio, conduzindo-o sub-repticiamente a sentir-se merecedor de ser abusado por outros (tutela, colegas ou pacientes, assim como por amigos, familiares ou companheiros) na expectativa de obter uma recompensa ou valorização compensatória em fonte externa (elogios, promoção de carreira, evicção do isolamento, estímulos afetivos, etc...).

Em vez de viver em intimidade congruente consigo mesmo, opta por viver em cumplicidade coerente com os que o rodeiam. Por muito que haja uma compensação inicial possível que crie um alívio transitório da insegurança intrínseca, as relações desiguais desativam os papéis de expressão das suas necessidades e impedem o reconhecimento da sua autenticidade, pelo que a médio prazo se tornam ainda mais bloqueadoras de uma realização pessoal. ${ }^{10} \mathrm{Na}$ perspectiva do autor, é uma "bola de neve" relacional que apenas conduzirá ao burnout final.

\section{Os movimentos de resgate}

Os movimentos de resgate dos profissionais das suas relações desiguais inserem-se nas estratégias da prevenção quinquenária e passarão, de forma sucinta, pela recuperação dos papéis ativos que lhes pertencem no seio de qualquer relação: autoconhecimento, reconhecimento, criatividade e expressão. A recuperação desses papéis consegue-se com um fluxo motivacional interno de viver em autenticidade e usando as diversas pequenas oportunidades cotidianas na comunicação com a tutela, colegas e pacientes ou nos momentos consigo mesmo. É possível que, no processo de ativação desses papéis, muitos dos profissionais tomem consciência das diferentes barreiras que encontram nas suas relações pontuadas por sentimentos de medo ou culpabilidade.

É também provável que "diagnostiquem" desigualdade ou abusos em várias relações que anteriormente considerariam saudáveis. Dessa constatação, poderão surgir reações emocionais opostas que, da mesma forma, mantenham as relações de forma desigual e apenas com fluxo oposto (ou seja, o abusado se torna o abusador). Tal não será tampouco benéfico. Haverá que relembrar que as relações se estabeleceram com determinados pressupostos para quais os profissionais tiveram a sua cota de responsabilidade e que, no outro polo das relações, provavelmente se encontra também uma pessoa a necessitar de ativar, da mesma forma, a sua autenticidade. Assim, o resgaste faz-se, portanto, de uma transformação interna gradual e consciente que, de certa forma, poderá inspirar os outros intervenientes nos seus próprios processos.

\section{Comentário final}

Os profissionais que se conhecem, que são reconhecidos por si próprios, que expressam livremente as suas ideias criativas e necessidades serão, provavelmente, profissionais mais felizes e tomarão decisões mais assertivas, ponderadas e com menos erros no cuidado do próximo. Como qualquer relação interpessoal, a relação médico-paciente é muito beneficiada com as medidas de prevenção quinquenária: há um profissional que é cuidado durante o processo do cuidado do próximo e há um próximo que recebe os cuidados refinados de quem se cuida. 


\section{Contribuição dos autores}

Concepção e delineamento do estudo: JAS. Aquisição, análise e interpretação dos dados: JAS. Redação preliminar: JAS. Revisão crítica da versão preliminar: JAS.

O autor aprovou a versão final e concordou com prestar contas sobre todos os aspectos do trabalho.

\section{Conflito de interesses}

Declara não haver.

\section{Referências}

1. Santos JA. Prevenção quinquenária: prevenir o dano para o paciente, actuando no médico. Rev Port Med Geral Fam. 2014;30(3):152-4. https://doi.org/10.32385/rpmgf.v30i3.11358

2. Carneiro M. Prevenção Quinquenária: um nível de prevenção esquecido? Lisboa: Médico.pt; 2017. [citado 2018 Ago 1]. Disponível em: http://www.jornalmedico.pt/opiniao/34259- prevencao-quinquenaria-um-nivel-de-prevencao-esquecido.html

3. Martins C. Quando o último deve ser o primeiro. MGFamiliar.2018. [citado 2018 Ago 1]. Disponível em: https://www.mgfamiliar.net/_blog/ $\mathrm{MO} /$ post/oup/

4. Collier R. Physician burnout a major concern. CMAJ. 2017;189(39):E1236-7. https://doi.org/10.1503/cmaj.1095496

5. Shanafelt TD, Noseworthy JH. Executive Leadership and Physician Well-being: Nine Organizational Strategies to Promote Engagement and Reduce Burnout. Mayo Clin Proc. 2017;92(1):129-46. https://doi.org/10.1016/j.mayocp.2016.10.004

6. Honavar SG. Healing the healer: Burnout prevention and rescue strategies. Indian J Ophthalmol.2018;66(5):611-3. https://doi.org/10.4103/ ijo.IJO_612_18

7. Dear JW, Webb DJ. Disease mongering -- a challenge for everyone involved in healthcare. Br J Clin Pharmacol. 2007;64(2):122-4. https://doi.org/10.1111/j.1365-2125.2006.02830.x

8. Brindley PG. Psychological burnout and the intensive care practitioner: A practical and candid review for those who care. J Intensive Care Soc. 2017;18(4):270-5. https://doi.org/10.1177/1751143717713088

9. Coulter A. Paternalism or partnership? Patients have grown up-and there's no going back. BMJ. 1999;319(7212):719-20. https://doi.org/10.1136/bmj.319.7212.719

10. Wexler DB. The broken mirror: A self psychological treatment perspective for relationship violence. J Psychother Pract Res. 1999;8(2):129-41. 